\title{
Rural catholic women in religious groups: experiences in identity formation in rural Mexico
}

\begin{abstract}
In this article I describe the behavior of rural Catholic women in the intersection between associations of the faithful and religious fiestas, as a node in which these women's membership in the community is configured and reproduced. As part of this process I give a synthesis of their gender, religious and community identities. The conceptual and ethnographic elaborations on which my analysis is based come from a research study in the field of feminist anthropology. The perspective from this particular field allows me to describe the way in which membership in religious groups for the women whose experience I reveal here has been closely linked to their membership in the community and their gender positions that, based on their bodies and sexuality, make it possible for them to develop certain powers. These powers are consistently characterized by subordination to and dependency on those occupying positions of authority in their contexts of interaction, in the framework of a rural locality in the southwest region of the Mexican state of Tlaxcala. The conclusion I reach emphasizes that these women find themselves in a paradoxical and contradictory situation, since they develop identities that are strongly characterized by protagonism at the individual level, and this is empowering for them, but it is based on limited powers that make it difficult for them to move on to political positions that would empower them beyond the individual sphere.
\end{abstract}

Keywords: protagonism, community, membership, carmelite association, individual level
Volume I Issue 2 - 2017

\author{
Martha Patricia Castañeda Salgado \\ Department of Social Anthropology, Ibeoamerican University, \\ Mexico
}

\begin{abstract}
Correspondence: Martha Patricia Castañeda Salgado, Department of Social Anthropology, Ibeoamerican University,
\end{abstract} Mexico,Emailmpcs05@yahoo.com.mx

Received: May 03, 2017| Published: August 22, 2017

\section{Introduction}

The study of women's participation in Catholic associations opens a door to understanding a specific form of interaction between women parishioners and the Catholic Church as an androcentric institution. These associations are part of the ecclesiastical structure and follow the norms established in the Code of Canon Law, which includes them under the category of "associations of the faithful." These are organizations for Catholic lay parishioners who carry out religious activities dedicated to a certain religious figure, together with evangelization work and community service work. They have their own internal rules and by-laws, although they must operate under the vigilance of the corresponding ecclesiastical authorities.

The analysis offered in this paper is focused on the study of the experiences of two groups of rural women, some of them belonging to the Daughters of Mary Association and others to the Carmelite Association. Based on their membership in one of these associations, together with appointments to certain positions within their internal structures, as President, Secretary or Treasurer, some women become the organizers of the religious fiestas corresponding to the religious figure that each association is responsible for. This allows them to confirm their membership in the community from an institutionalized ubi (the social, philosophical and political place that a subject occupies in the world). This situation, which is repeated in different rural and urban localities, has a specific characteristic in the case of San Francisco Tepeyanco, Tlaxcala (Mexico). For the women in this locality, belonging to an association of the faithful is necessary in order to be in charge of a religious fiesta unlike for men, who may do so on the basis of their participation in the local community cargo system. This signifies that for women, being Catholic is more than a life circumstance. It is a requirement in order for their participation in festive and ritual practices (which constitute an important identity referent for the local population) to be recognized with authority and prestige. The above leads us to the consideration that we are witnessing a cultural situation in which the gender condition intersects with the religious condition and community membership, leading to a process of cultural reproduction in which speaking of a Catholic woman from Tepeyanco implies referring to the constitution of a specific subject that synthesizes those elements of identity, together with the sociopolitical positions that together they carry with them.

\section{Conceptual considerations}

The conceptual and epistemological focus of this article, as well as of the study on which it is based, is to consider women as subjects of gender whose constitution is historically and culturally defined on the basis of the concurrence of different processes, that range from the assignment of gender on the basis of the female sexed body, to the acquisition of subjectivity specializing in what is female that orients the lives of those possessing such. This assumes the validity of a conception of the world in which women and men, female and male, appear as the socially recognized forms of being human. It is important to emphasize, however, that these are specializations in which women and men acknowledge each other, while at the same time establishing exclusive definitions. The dynamics between the exclusivity and exclusion accompanying the conformation of women and men as subjects of gender assumes the identification of each of them within a social hierarchical organization in which this condition is combined with conditions of class and/or ethnic group, assuming a differentiated, unequal distribution of powers and privileges to which some women and some men may gain access to. In this process in 
which women are constituted as subjects, gender is presented as a particular nucleus of signification for the confirmation of the specific identity in which the body is the basic referent, and the grounds for their history lie in their experience.

The importance of the body in the construction of gender identity and conceptions of the world go hand in hand with sexuality, since both are centers of reflection and of generation of both significations and powers. This is one of the dimensions in the constitution of gender that makes it possible to conceive of gender as a social creation that is always relational and political. In this sense, power operates as a basic principle for the conformation of modern subjects characterized by autonomy, separability and independence, ${ }^{1}$ as well as self-regulation, discernability and the capacity for individuation. ${ }^{2}$ All of these characteristics are restricted or denied to women, who cannot name themselves and are therefore excluded from "poder poder" (being able to be able to)". ${ }^{3}$ It is essential to mention that gender is a political construction in which there is intervention by the State through its institutions, as well as by other institutions parallel to the State. Thus, the State directly regulates the relationships between women and men, and indirectly supports all the mechanisms that protect the established order in relation to their gender condition as women or men. Some corporatist forms of organization operate as mediators between individuals and the State, as in the case of family and community. There are lines of shared significations between them in terms of the dimensions of gender-based social organization, thus contributing to their permanence and continuity over time. In this way, family and community become political arenas in which an internal confrontation for control over women through their bodies takes place. These are political arenas in which the institutional actions participating in the conformation of hegemonies are expressed. Clearly expressed in this dispute for control over women is a binary way of thinking that is articulated around opposites: women-men, nature-culture, humansuperhuman. This binarism is part of a conception of the world that enters into profound harmony with religious thought.

In patriarchal societies, there is an intimate link between gender, religion and identity. This link is embedded in subjectivity and constitutes the reference point from which each individual belonging to a religion finds their way in the world. Understanding religions as "totalizing systems of meaning", ${ }_{4}$ it can be said that they contribute symbolic contents to gender constructions, by placing them in a cosmogonic order in which what is human interacts with conceptions of the divine, sacred and supernatural. And thus, an area of definition is specified for the meaning of "what one should be," in the case of Catholicism, based on morality. One of the expressions of this "should be" is the configuration of essential identities that reinforce the exclusive nature of being a woman or being a man.

\section{Catholic women as a social category}

From my perspective, Catholic women are those who, as members of the Catholic Church, have deeply and definitively integrated into

'See Seyla Benhabib, Drucilla Cornell, Teoría feminista y teoría crítica. Ensayos sobre la política de género en las sociedades de capitalismo tardío. Valencia. Edicions Alfons El Magnánim-Institució Valenciana d’Estudios I Investigació. 1990.

${ }^{2}$ See Celia Amorós. "Espacios de los iguales, espacios de las idénticas. Sobre poder y principio de individuación," in La gran diferencia y sus pequeñas consecuencias... para las luchas de las mujeres. Madrid. Ediciones Cátedra. Colección Feminismos. 2005.

${ }^{3}$ lbid.

${ }^{4}$ See Manuela Cantón Delgado, La razón hechizada. Teorías antropológicas de la religión. Barcelona: Editorial Ariel. 200I. I4 p. their lives the intricate link between the religious culture ${ }^{5}$ and gender culture $^{6}$ corresponding to that particular religion. Catholic women constitute a social, religious and political category in which the vital experience of women is organized by religious beliefs and practices that assign them a place of subordination in both human and divine spheres. These women are also characterized as carriers of a mentality constituted on the basis of the distinction between body and soul, as well as a moral orientation in which virtue and sin are mutually opposed. This mentality is articulated with social relationships and practices in which the body, sexuality, maternity and the set of possibilities for women's lives and their futures are the reference points. At the same time these women serve as depositaries, reproducers and protagonists of the norms for life characterized by this particular religious-genderway-of-being. From the perspective of the anthropology of religion, the set of beliefs that make up Catholicism is constantly re-created through three practices: the confirmation of myths, rituality and religious acculturation. Catholic women are essential for all three of them, since through their everyday practices, they guarantee the permanence of this religious perspective, in terms of time as well as the lives and memories of those professing this particular religion.

It is necessary to pause here to introduce the following consideration: despite universal prescriptions, there are different ways to be a Catholic woman, and there are also different models of femininity transmitted by the Church throughout its institutionalization process. One especially worth mentioning, however, is the Marian model that emphasizes virginity and maternity in terms of how women "should be." In the specific case of San Francisco Tepeyanco, it is possible to distinguish between women who are "believers," "Catholics" and "the renewed." Believers are women who define themselves more in terms of their beliefs and faith than their relationship with the church. They tend to be critical of priests (ministers of the Catholic religion, officials of the ecclesiastical wing of the church's internal organization), who they consider to be functionaries at the service of the people. Catholics, in contrast, are characterized not only by their faith but also by an extremely close relationship with the church through their intense participation in parish activities. For these women, priests are spiritual leaders with whom they collaborate and to whom they turn for advice and consolation. Those identified as renewed are the women who follow the pastoral position within the Catholic Church known as Charismatic Renewal in the Holy Spirit. Unlike believers and Catholics, these women not only participate in the rituality and service to the church, but also develop healing capacities and are actively involved in religious acculturation. Catholic women from San Francisco Tepeyanco in these three categories may be members of local associations of the faithful, and in some cases may belong to more than one of them.

Whatever the specific category these Catholic women belong to, we find that priests intervene in their religious practices. This is especially true for the parish priest, who is responsible for defining the distinction between the cultural practices expressed in the community

${ }^{5}$ With this term I am referring to a particular dimension of culture, coded in a conception of the world developed around what is sacred, which is specific, intangible and liminal. In religious culture, a relationship of mutual determination is established between the ideas of nature and the supernatural in which human action operates on them while at the same time it is constantly given meaning through this link.

${ }^{6}$ Gender culture is another dimension of culture in which the development of what is human is something specific and split on the basis of sex. It leads to a prolongation of human characteristics to all which is affected by the mentality and actions of women and men. 
religious cargo system held by men (fiscales and mayordomos) ${ }^{7}$ and the practices promoted by the church itself-which guarantee lay women a place within the institution's everyday activities.

\section{Local context}

The locality where these women reside, as mentioned earlier, is San Francisco Tepeyanco. This rural settlement is located in the southwest part of the Mexican state of Tlaxcala. According to demographic data, ${ }^{8}$ it had a total of 3,019 inhabitants $(1,605$ women and 1,414 men) in 2005. In socioeconomic terms, it can be characterized as an example of the new Mexican rusticidad, a term coined by Patricia Arias $^{9}$ to refer to the socio-spatial and economic contexts in which agricultural work is combined with other income-generating activities (waged work, self-employed work and commerce, to mention the most important), and with multiple effects left by economic modernization in the localities in the Puebla-Tlaxcala region. In cultural terms, this locality can be considered a post-Nahuatl ${ }^{10}$ community in which a fundamental identifying characteristic continues to be an extensive ritual and festive cycle that combines celebrations related to agricultural cycles, Catholic saints' days and community celebrations. The number of fiestas celebrated throughout the year makes it possible for many individuals to become involved in this cycle, which is maintained by networks of relatives and friends, and is interwoven with economic exchanges, rituals, shared beliefs, acknowledgement of ethnic identities, and material or symbolic goods that express the different veins of a shared history. In this context, Catholicism has acquired elements from its cultural competition with the native

${ }^{7}$ Community religious cargo system are the form of political organization used by the pueblo, which is the category used locally to refer to the community. The most important cargos are the fiscales, who represent the rumbos (territorial districts) in the locality, and the mayordomos, who are responsible for the devotional practices revolving around the worship of each saint venerated in the community. All of those holding these cargos are elected in assembly, through direct voting. This makes them socially representative, increases their authority and allows them to move on to fill a civil political post. Only men can fill one of these cargos. Women are excluded, with the exception of a lower position as a xochimayordoma, in charge of the daily cleaning of the church.

${ }^{8}$ The source of these figures is: II Conteo de Población y Vivienda 2005. Mexico: INEGI; 2005.

${ }^{9}$ See Patricia Arias. Nueva rusticidad Mexicana. Mexico: CNCA. 1992.

${ }^{10}$ Here I use the concept of community proposed by Cristina Oehmichen Bazán, referring to a cultural collectivity based on a set of significant primary relationships by virtue of the fact that its members share common symbols that refer to a real or supposed shared origin and histories, and to their relationships as relatives. It may also be defined, according to Oehmichen Bazán, as a form of primary social integration that generates links characterized by primordiality in relation to other social attributions or memberships. She emphasizes that community is no longer viewed as merely a territorial, legal unit, and instead is conceived of as a fundamentally cultural construct, as a unit of belongings and loyalties, or a community of rights and obligations that involve criteria for membership. See Cristina Oehmichen Bazán, Identidad, género y relaciones interétnicas. Mazahuas en la ciudad de México. Mexico: IIA-UNAM; 2005. 3I p. Also, Eileen M. Mulhare coined the term "postNahuatl" to refer to the coexistence of Nahuatl cultural elements (with the exception of language) and cultural elements originating from the population's incorporation into regional industrialization processes. The synthesis offered by this author is applicable to the case of Tepeyanco. She states that while life in Totimehuacán, the locality in the state of Puebla that she studied, is "closely linked to Mexico's urban industrial present and future, its social and religious life reflects its Nahuatl heritage and its colonial past" (unofficial translation). See Eileen M. Mulhare, "Respetar y confiar: ideología de género versus comportamiento en una sociedad post nahua," in David Robichaux (comp.), El matrimonio en Mesoamérica ayer y hoy. Unas miradas antropológicas. Mexico: Universidad Iberoamericana; 2003. 269 p.
Nahuatl culture, as well as the transformations experienced by this culture since the 16th century as a result of its subordination first to the Spanish crown, and then to the culture promoted by the Mexican State. And here we must also add the presence of other religions in the locality, municipality and region. ${ }^{11}$

In addition, the fact that the local Catholicism has developed in a rural setting makes it a religion closely associated with the subjective needs of the rural population, subjected to both market demands and the fluctuations characterizing nature. As a result, the religiosity of women and men in San Francisco Tepeyanco is marked by an extensive set of practical activities and religious practices, associated with the requirements for everyday reproduction. This has made it possible for Catholicism to become part of the local ethnicity-if we understand the latter to be the conformation of a community identity in which the Nahuatl culture continues to be a central reference point, however interpreted within an identity as a parish.

\section{Women from san Francisco tepeyanco in local associations of the faithful}

Associations of the faithful are organizational forms designed by the Catholic Church to bring together the lay population around its pastoral projects of social, ideological and political influence. Generally, they are associated with a religious order that protects and orients them. These associations are part of a hierarchical institutional organization at the international level. At the same time, each of these associations has an internal structure that is also hierarchical, and at the base level we find precisely the associations operating in rural parishes. Parishioners belonging to rural associations of the faithful are mostly individuals who have limited economic resources but are not poor. This is because participation in the required activities involves a series of expenses that are out of reach for those who are barely surviving. This is also true for those belonging to associations in urban neighborhood parishes. However, there is a difference in that they are farther removed from the higher organizational levels of these associations. At the regional level, there is the parish level and coordination at the diocesan level, and then there is coordination at the provincial and regional levels. Further beyond, associations operate at the national and international levels, with the highest level consisting of the representations that report directly to the Vatican. For the immense majority of rural parishioners, they are unaware of these levels. And for those who have integrated themselves enough to learn about this structure, such levels are beyond their reach. Nevertheless, the social, political and geographical distance separating them from the top hierarchical levels of these associations at the international level does not diminish the control exercised over local parishioners by leaderships in which ecclesiastical and lay authorities are established. What this distance does allow for is that parishioners use their own codes to interpret the prescriptions they receive from these authorities. Associations of the faithful can be mixed, including both women and men, or may include only women or only men. They are composed of a governing body and a group of members who become such after meeting a set of accumulative requirements. The members select the individuals to serve in the governing body by a voting process.

\footnotetext{
"According to data from 2000 , of the 8,024 people inhabiting the municipality of Tepeyanco, 7,28I identified themselves as Catholic. This proportion is the same in the San Francisco Tepeyanco locality, in which there is a minority of evangelical families who, because of their religious membership, are excluded from most of the social practices that contribute to the community's cohesion, and establish their social relationships outside of the community. See XII Censo de Población y Vivienda. Mexico: INEGI; 200 I.
} 
Of the different associations in San Francisco Tepeyanco, I selected the Daughters of Mary and the Carmelite Association because their respective religious fiestas are the most representative of those referred to in the locality as "women's fiestas." Furthermore, as I will explain below, each of them encompasses models of femininity that address women of different ages, offering ideas regarding one's body and sexuality that reveal specific elements for the particular life cycle that members are going through.

I began with the Daughters of Mary Association, established in France in 1835. In 1847 the female branch of this association was approved, and in 1850, the male branch, with the resulting changes in its name to the Daughters and Sons of Mary Association. It is governed by statutes, regulations and a prayer book, with both an ecclesiastical and a lay focus. In 1999 it was confirmed in the Vatican, and its International Statutes were approved. From its beginnings to the present time, it has expanded from Europe to Africa, Asia and the Americas, and it has been renamed and adapted to the contexts in these regions, without losing the characteristics of its internal organization based on a governing body and various categories of members. While members of all ages are accepted, it is especially focused on participation by young people. Among its operational mechanisms, especially worth mentioning are its periodical conferences. This Association is distinguished by its conservative political orientation. In Mexico it maintains close links with other similar associations, such as Catholic Action and Perpetual Adoration. In addition, it includes members from Catholic social organizations such as the Christian Family Movement, Unión Nacional Fememina, ProLife, Knights of Columbus and Legionaries of Christ, to mention some of those currently having the most influence on Catholic parishioners. This link among Catholic social organizations and associations makes it possible for them to operate as a political front in response to leftist political tendencies and feminism, and in response to those they confront in public debates and references at local, national and international levels. In this sense, it constitutes the Church's lay branch of political action, at the level of the pastoral work carried out incessantly by members, including charity-type activities as well as actions that permit them to have influence on public opinion.

Nevertheless, these postures developed in the Vatican and transmitted through the association's hierarchical structure reach rural parishioners through the interpretations expressed by parish priests, who attempt to adapt them to the rural context and consequently end up transmitting the postures of Mexico's ecclesiastical hierarchy more than those of the higher level. This is one of the reasons explaining the plurality in manifestations of Catholicism in countries like Mexico, responding to both processes of syncretism between Meso-American religions and European Christianity that date back to the colonial system, as well as to these processes of interpretation that, at the same time, reflect the heterogeneity and social inequality characterizing the members of Mexico's clergy. The Carmelite Association, for its part, is the oldest of the two, and I will dare say, is even more archaic than the other. Its origins date back to the sisterhoods and brotherhoods emerging from the Carmelite Third Order approved in 1452 which over the course of centuries became the Carmelite associations of the 20th century. This Association is also mixed, and is much more oriented toward devotion and prayer than public action. Its historical permanence can be explained by its contemplative nature, through which members develop their internal, personal lives, and therefore do not attempt to have an impact on the environment around them. Their meetings are of a fundamentally pastoral nature. In terms of class, it can be said that unlike the Daughters and Sons of Mary
Association, which includes people of all socioeconomic levels, the Carmelite Association has more influence in the middle-level and poor sectors of society, both urban and rural.

Specifically, focusing on the locality of reference, there were 150 women in Tepeyanco who belonged to the Daughters and Sons of Mary Association in 2006, and 120 who belonged to the Carmelite Association. ${ }^{12}$ It is important to specify that, while both associations are mixed, with both female and male members, they are viewed in the community as women's associations. This is both because their patron saint is a virgin, and because most of their members are women. This may be part of the gender division of the world observed among the local population, which tends to specialize women and men in terms of what they do in spaces, contexts, activities, practices and relationships, either feminizing or masculinizing them, whichever the case.

In each association a President, Secretary and Treasurer are elected every year, and the functions of these positions are defined in the statutes developed for each of them. Generally speaking, the President coordinates members' activities, particularly those related to organizing the fiesta dedicated to Mary, the object of their devotion, and she is also responsible for admitting new members, promoting pastoral activities and attending diocesan meetings or conferences. The Secretary, for her part, is responsible for the association's record books, in which she maintains the association's inventory of goods updated, as well as the minutes for events held. Lastly, the Treasurer is in charge of collecting the fees assigned to each member for each particular event, for doing the accounting and distributing financial resources in line with purchases or expenses proposed by those in leadership positions when taking office. The official name, Daughters and Sons of Mary Immaculate Association, has been reduced by the local population to simply Daughters of Mary, which better expresses its current characteristics. Although in official terms, this association is responsible for celebrating the fiesta of the Immaculate Conception of Mary every December 8, it is responsible in this particular locality for the fiesta corresponding to the Assumption of Mary on August 15. In addition, members are in charge of celebrating the month of Mary, meaning that during the entire month of May there are activities, mass and especially, the ritual of children from the locality "offering flowers" to the Virgin.

In terms of local membership, women of all ages belong to this association. However, the leadership positions are reserved for young women whose virginity is beyond question. For this reason, it is almost a rule that a young woman between 15 and 20 years of age serve as president, although there are some exceptions. The president is elected by members fulfilling all membership requirements specified in the statutes. This means they have passed through the various age and conjugality groups identified as: "Mary's angels," composed of young girls and boys from the moment they become members of the association up to the age of five; the group of girls from five to ten years of age; the group of girls from ten to 15 years of age; the group of young women including those 15 years of age and up to the time they marry or enter into a conjugal relationship; and the señoras, women's group including all women older than 15 years of age who have established a conjugal relation. The transitions from one group to another are acknowledged through a special distinctive object consisting of a Miracle Medal hanging from a ribbon of a different color for each of

\footnotetext{
${ }^{12}$ See Martha Patricia Castañeda Salgado, Las mujeres católicas en las asociaciones religiosas: fiestas, poderes e identidades. Doctoral dissertation in Anthropology. Mexico: UNAM; 2007.
} 
these groups, until reaching the level of a member, who then uses a ribbon of light blue, corresponding to the iconographic representation of Mary's clothing. All members have voice and vote, as long as they have fulfilled their obligations, but especially as long as they are up to date on paying their fees. The Carmelite Association is also mixed. Although there are more women than men, the number of men is not as limited as in the Daughters of Mary. In complete contradiction to its pastoral orientation, which emphasizes humility as an attribute of those who follow the teachings of the Virgin of Carmen (the object of devotion in this association), those who join this association are adult, older women who are married and especially those who work in commercial endeavors and who have their own income. As a result, their economic capacity makes it possible to celebrate one of the most lavish fiestas in the community. One becomes a member by joining the association, and there are no internal distinctions as in the case of the Daughters of Mary. There is only one distinctive object for all female and male members: the scapular.

\section{Identity contents derived from membership in daughters of mary}

We will now focus on the set of identity contents that are transmitted to Catholic women through the norms, practices and relationships prescribed by the Daughters of Mary Association. It is important to begin by emphasizing that this association focuses its discourse on reflecting upon the four fundamental virtues of Mary, the mother of Jesus, ${ }^{13}$ specifically: purity, humility, obedience and chastity. These virtues are the basis for defining the social contents and symbolic meaning of virginity (primarily the first), referring directly to "virginal purity," symbolized iconographically by a white lily. Also accompanying these virtues is, first of all, modesty, an attribute that is both internal and external, since it involves a set of attitudes and a way of handling one's body that includes voice modulation, manners of dressing and walking, and especially, the way in which one looks with one's eyes, since they are the "windows" through which temptations may enter and through which one's soul may die. Secondly, there is charity, a dual attitude that includes love for God and love for one's neighbor. Institutional support for these virtues is provided in the Manual for the Daughters of Mary Immaculate. This manual presents all the qualities, values, norms and prescriptions that the association transmits to its members. The association is defined in the Manual as a unit of body and soul in which each one of its organizational entities is compared to an organ that fulfills a vital and irreplaceable function. The association is also presented as a family in which Mary is the mother, the authority is the father, and the members are sisters (and obviously, daughters). Nevertheless, at the earthly level, the first two positions have a functional materialization: the father is the association's director, while the president is the mother. All of these orientations and prescriptions are assumed by Tepeyanco women from their own cultural codes. And they manifest the enormous difficulty they experience in responding to each of the imperatives represented by the virtues, particularly humility. This is because, living in a

${ }^{13}$ Within the doctrinaire corpus of Christianity, Jesus was the son of God who was sent to the Earth to pay for the sins of humanity, and thereby fulfill the pact established between his Father and mortals. To this end, he became flesh in Mary, a young woman who was chosen to carry him in her womb, and who brought together two particular qualities: having conceived without original sin and remaining a virgin before, during and after the birth of Jesus. This was because her pregnancy was the work of the Holy Spirit, without physical intervention by Joseph, her future husband. These characteristics make her an example to follow, and at the same time, a model that mortal women can imitate but never equal or repeat. clearly stratified society characterized by possibilities for moving up the social ladder to the degree that they accumulate sufficient social, economic and symbolic capital in order to change their level and status, it is difficult to remain completely detached from the pride and arrogance that arises from positioning oneself above other women, particularly when they are relatives with whom everyday relationships are not very harmonious. This attitude of creating distance from others goes against the corresponding Catholic teachings as well as the ethnic community principles of mutual assistance, cooperation and reciprocity-which are frequently practiced but always with the implicit expectation of receiving more or less the same as given.

Obedience, in contrast, is a value, an attitude, a behavior and an orientation for social relationships that women in the locality have internalized very well. In practice, it is one of the guiding principles in their personal, family, community and social lives. Since they were very young, they were taught to obey all authority figures, from their father and mother to national authorities and the Pope, the maximum leader in the Catholic Church to whom they will never come close to physically, but he appeals them through sermons and talks given by priests, and through sporadic appearances on television the communication medium that can be found in all the local homes. Developing discipline around obedience is something that comes to the daughters of Mary through other previous means: family acculturation and formal education. Therefore, the Marian doctrine transmitted to them when they attend the periodic association meetings, together with the precepts they should learn from the Manual and other religious publications to which they have access, find already fertile ground for easy understanding and better acceptance by the majority of girls and young women belonging to this religious group. Virginity, however, is a moral principle that finds greater difficulties in becoming a norm in the lives of Tepeyanco women. On the one hand, they understand that Mary's virginity is an example to follow, but on the other, they live in a rural context in which exercising heterosexual sexuality is an area in which there is competition from the influences of indigenous marriage,,$^{14}$ the effects of migration, and the vital satisfaction of sexual desires. In these conditions, young women in the community find it difficult to replicate the virtue of purity in the strictest sense until the moment they contract religious matrimony. Thus, the election of the association's president is based particularly on the social perception of the virginity of the young woman to take on this responsibility. Introduced into the concept of virginity are elements corresponding to individual behavior (a modest, obedient, respectful young woman with good habits, and someone who has not been spoken negatively about in relation to boyfriends) and family behavior (that she comes from a family whose integrity has not been questioned).

It is important to add to the above that, since the Daughters and Sons of Mary Immaculate Association was established in the community during the 20th century, women of different ages have received, with varying intensity, the emphatic message of virginity

${ }^{14}$ Soledad González Montes has described with great detail the particularities of indigenous marriage, conceived as a process which, although with local variations, encompasses a complex ritual beginning with asking for the bride and engagement. In this process, however, there are socially tolerated practices such as stealing the bride after which the couple asks for forgiveness, having decided to begin their life as a couple before closing the ritual cycle. See Soledad González Montes, “Las 'costumbres' de matrimonio en el México indígena contemporáneo," in Beatriz Figueroa Campos (coord.,), México diverso y desigual: enfoques sociodemográficos. $\vee$ Reunión de investigación sociodemográfica en México. Volumen IV. Mexico: El Colegio de MéxicoSociedad Mexicana de Demografía; 1999. 
as an absolute gender precept in relation to what a woman should be. The most elderly women report that when they were young there were more important associations in which being a muchacha (a virgin, according to local use of the language) was not a requirement to become a member. In contrast, middle-aged women, whose ages place them in the process of the association's consolidation at the local level, remember that priests transmitted the importance of virginity, urging young women to join the Daughters of Mary in order to publicly demonstrate their sexual condition. In fact becoming a member of the association had been a fundamental milestone for them when they were young and single. This was especially true for those who managed to obtain one of the leadership positions. They reported that by filling one of these positions, they were identified as responsible young women, with the acquired right to find a "good husband" and demand good treatment from him, for having come to the marriage without prior sexual relations with him or any other man. This circumstance was such a determining factor in the lives of these women that they have been those who most actively urge their daughters to become members and to aspire to becoming president secretary or treasurer of the association. The result of these efforts can be summarized in the construction of a genealogy of the women who have filled these leadership positions throughout at least three generations.

\section{Identity contents derived from membership in the carmelite association}

In a way that complements ${ }^{15}$ the virginity value dedicated to the Assumption of Mary, the Virgin of Carmen represents the mature mother-woman, and consequently, women's maturity-an image that has been appropriated by women who have married "well" (in other words, who have already carried out the ecclesiastical ritual of marriage), who are mothers and who have a stable economic situation. It is therefore not surprising that the women most interested in belonging to the Carmelite Association, and in filling one of the leadership positions, are women involved in commerce. They are different from other women in that they have their own income, they are active outside the community without being "viewed poorly" since they carry out activities that the local population considers to be traditionally female, and they have the potential to save money and thus experience fewer economic restrictions. In terms of gender values, the Virgin of Carmen represents the mother who takes care of her daughters and sons in health and in sickness, and who is ready to intercede on their behalf when the occasion merits. In particular the focus is on the mother who is concerned with the well-being of her offspring and all the family members around her. She is also a protective mother, and this is a posture that is symbolized in the scapular which, unlike the distinctive objects linked to the Virgin of the Assumption, should accompany the person carrying it during their life and also in death. It is assumed that the Virgin of Carmen not only fulfills the assignations mentioned above, but also accompanies women and men who are in the process of dying, to enable them to enjoy a "good death." In clear opposition to the principles of humility and poverty apparent in Franciscan doctrine, the local version of this

\footnotetext{
${ }^{15} \mathrm{On}$ this point it is important to call attention to the fact that in Nahuatl axiology, complementarity is a basic principle for the formation of vital or meaningful units. Along this line, nothing defines itself on its own, but rather through the existence of a complementary entity to which it is opposed. It can be assumed that this philosophical perspective is present in the assignment of particular symbols and significations that the Tepeyanco population has granted to the two dedications to Mary analyzed in this study.
}

virgin has been adorned with a status that makes her appear to be a distinguished, dignified woman, making her worthy of one of the most lavish fiestas in the community's ritual and religious festive cycle. This is in clear harmony, then, with the status enjoyed by businesswomen, who go to great efforts to make an outstanding impression on the occasion of the religious fiesta, with great fanfare around their personal appearance.

Carmelite Association members receive religious training in which the contents on gender are complementary to those transmitted by the Daughters of Mary. While for the latter group the norms established for the bodies and sexuality of women are based on their virginity, the norms for the Carmelites are focused on the sacred responsibility of taking care of their daughters and sons all throughout their lives. While there is no clear or direct relationship, it is said that expectations for the members of this association are derived from the Rule of the Secular Carmelite Order or the Carmelite Third Order. Specifically, these women are expected to be patient with their husbands, to not fall into the temptation of infidelity, and to learn to forgive any mistreatment received. In addition, with most of the women over the age of 40 , it is implicitly assumed that they are in a process of desexualization since they are moving out of their reproductive years, when there was an urgent need for having sexual relations. Under these assumptions, they are now expected to dedicate more time to prayer and to helping take care of the church, in both practical and symbolic terms. They are assigned the responsibilities of fidelity, charity, the spirit of service and cooperation for salvation, and are therefore not only urged to promote Christian spirituality, but also to defend their religion against the enemies around them.

\section{Religious training and gender culture}

Membership in lay associations during the course of women's life cycles thus allows each of them to receive the necessary discourses and prescriptions for their particular age at any time: virginity and purity for girls and young women; maternity and spirituality for middle-aged and older women. In the women's interaction with the broader gender culture, and the ideological components of which are associated with Catholic training, it is possible to identify points of harmony, contradictions and negotiations in the area of individual existence, and also in the social change gradually experienced by the community. Among the points of harmony, I would like to highlight one example. In the locality studied, two modalities of inheritance are practiced: one that gives priority to sons over daughters, and the other based on homogenous inheritance, in which sons inherit from fathers, and daughters inherit from mothers. Although land and the paternal home are inheritable goods par excellence, women tend to pass other things from one generation to another. While these things may fit within the characterization of residuality as proposed by Soledad González, ${ }^{16}$ they are among the resources through which women participate in the reproduction of local gender organization. Thus, women give their daughters and granddaughters only limited material goods, but they give them symbolic goods that allow them to place themselves in social positions of negotiation, or at least maintain them in those positions.

\footnotetext{
${ }^{16}$ See Soledad González Montes, “La reproducción de la desigualdad entre los sexos: Prácticas e ideología de la herencia en una comunidad campesina (Xalatlaco, State of Mexico, 1920-1960),' in Josefina Aranda Bezaury (comp.) Las mujeres en el campo. Memoria de la Primera reunión nacional de investigación sobre mujeres campesinas en México. Mexico: Universidad Autónoma Benito Juárez de Oaxaca; 1988.
} 
Using this logic, I was able to detect some cases of women whose membership in one or the other religious association was passed on to one of her daughters or was argued over by her daughters. To inherit the distinctive object of belonging to an association signifies maintaining the position occupied by the mother in that association, but without having to go through the entire process of passing through different categories in order to become a member with the corresponding rights and obligations. This practice, of course, contradicts the norms established by the associations. However, it does express a form of connection between membership in the associations and cultural practices that strengthen the identity links of gender, through both family and community. In terms of contradictions, the distance between the ideal of virginity and real sexual life clearly and unquestionably expresses the distance between moral religious discourse, the matrimonial process based on indigenous roots, and restraint over desire. In terms of regulating sexuality, the norms established by the Daughters of Mary appear as a technology of gender aimed at controlling the bodies and sexuality of young women through a patriarchal process that Celia Amorós ${ }^{17}$ has defined as the de-identification among women based on placing some of them in positions of exceptionality. It also expresses, however, the confluence of gender mandates derived from both Catholicism and Nahuatl morality. In the latter women's virginity is also highly valued since it expresses the capacity of young women to bring their impulses under control in the present in order to assure a good future. The above sets the stage for women's negotiations with other social actors with whom they interact throughout the course of their lives. Through their virginity and by demonstrating attitudes such as obedience, respect for authority, honesty and humility, women in line with local values become empowered. Having married as virgins allows women to place themselves in positions in which they can use this sexual condition as an argument for exempting themselves from mistreatment and humiliation. Even though in practice they may be the object of violence in their conjugal or family relationships, women can always use this condition as part of the symbolic capital that grants them respectability.

\section{Final considerations}

The discourse, practices and social relations derived from membership in the religious associations studied has allowed the women who belong to them to establish themselves as social subjects in a context in which Catholicism is an intrinsic part of local ethnicity. Through these associations, women acquire certain prestige, hierarchy and social recognition - which women not joining the associations lack, and at another level, which only those who fill leadership positions in the associations have, in comparison to other members who are not elected to such positions. Using this logic, and within a profoundly androcentric society, these women become

\footnotetext{
${ }^{17}$ Celia Amorós, op.cit.
}

carriers of "status-centricism", ${ }_{18}^{18}$ which distinguishes them from other women, although it does not, in this process, bring them closer to men. Tepeyanco society, like many other rural societies of Nahuatl origin, maintains a strict separation between male and female spheres. These spheres are presented ideologically as complementary in nature, however in social, cultural and political terms they endorse women's subordination. Catholicism contributes to this subordination, from the perspective of its conception of the world to its institutionality, thus entering into a profound intersection (also interpreted as syncretism) with this social order of gender. In this context there is meaning in the fact that women belonging to local dominant groups make major, ongoing efforts to belong to a Catholic association in order to act simultaneously as representatives of this association in relation to the community and to represent the community in relation to the church. In this way they become political intermediaries within a structure that allows them restricted access at a corporatist (never individual) level to limited, temporary positions of public authority.

Prestige, even when transitory, is perhaps the greatest social benefit obtained by these few women by filling leadership positions in religious associations. Through this achievement, furthermore, they obtain a place for themselves in the community's history. While they do not remain present for a long time in the memories of the Tepeyanco population, the names of the presidents, secretaries and treasurers remain in the record books of these associations, in the inventories of the virgins' belongings, on the plaques on the altars they had built or remodeled, and also in their relatives' genealogical records. Organizing a good fiesta, giving away distinctive objects of good quality, making respectable donations to images and to the church, as well as presenting complete records to the other members are all actions that remain in the memories of those who witnessed the performance of those holding leadership positions, transforming them into symbolic marks that make them worthy of becoming reference points for their successors. And in this way they contribute to the continuation of the local culture of gender, recreating the display of women's capacities, while always remaining within the limits of the synthesis of gender, religion and ethnicity, as established by the community's patriarchal culture.

\section{Acknowledgements}

None.

\section{Conflict of interest}

The author declares no conflict of interest.

\footnotetext{
${ }^{18}$ Andrée Michel uses this term to refer to the tendency to place the values of the group to which one belongs as a measuring stick for the values characterizing other groups. This serves to maintain hierarchical relationships, and is thus similar to both ethnocentrism and classism. See Andrée Michel, EI Feminismo. Mexico: Fondo de Cultura Económica; 1983.
} 